\title{
Hepatoprotective activity of the ethanol extract of Curcuma heyneana rhizome on isoniazid and rifampin-induced liver injury rats
}

\author{
Marianne Marianne ${ }^{1,2^{*}}{ }^{\mathbb{D}}$, Urip Harahap ${ }^{1,2}$, Poppy Anjelisa Zaitun Hasibuan ${ }^{1,2}$, Chintya Monica Thampati $^{1}$, Herman \\ Syukur Harefa ${ }^{1}$ \\ ${ }^{1}$ Department of Pharmacology, Faculty of Pharmacy, Universitas Sumatera Utara, Medan 20155, Indonesia \\ ${ }^{2}$ Nanomedicine Centre, Universitas Sumatera Utara, Medan 20155, Indonesia
}

\section{A R T I C L E I N F O}

Article Type:

Original Article

Article History:

Received: 13 March 2019

Accepted: 10 October 2020

\section{Keywords:}

Curcuma heyneana

Hepatoprotective

Rifampin

Isoniazid

Antioxidant

\begin{abstract}
A B S T R A C T
Introduction: Isoniazid (INH) and rifampin (RIF) are antituberculosis drugs that can induce injury in the liver. The purpose of this study was to investigate the antioxidant and hepatoprotective activities of the ethanol extract of Curcuma heyneana rhizome on liver injury in animal model induced by INH and RIF.

Methods: Antioxidant activity was measured by using 2,2-diphenyl-1-picrylhydrazyl (DPPH) method. All animals were divided into 7 groups. Liver injury was induced by using combination of INH at the dose of $50 \mathrm{mg} / \mathrm{kg}$ and RIF at the dose of $100 \mathrm{mg} / \mathrm{kg}$. These drugs were administrated for 15 days along with extracts at doses of 5, 25, 125 or $625 \mathrm{mg} / \mathrm{kg}$. Positive control group was given catechin. On the $16^{\text {th }}$ day, the rats were sacrificed, blood and livers were collected for assessment of biochemical parameters like alanine transaminase (ALT) and aspartate transaminase (AST) and histological studies, respectively.

Results: The ethanol extract strongly scavenged DPPH with inhibition concentration $50\left(\mathrm{IC}_{50}\right)$ of $82.48 \mathrm{ppm}$. Administration of ethanol extract of $C$. heyneana rhizome at the dose of 25, 125 or $625 \mathrm{mg} / \mathrm{kg}$ significantly inhibited the elevation of AST and ALT $(P<0.01)$. Moreover, the effects caused by administration of the extracts were similar to the effects caused by catechins. Various doses of the extract could effectively reduce tissue damage.

Conclusion: This result suggests that ethanol extract of $C$. heyneana rhizome at the doses of 25, 125 and $625 \mathrm{mg} / \mathrm{kg}$ might be effective as hepatoprotective agent.
\end{abstract}

Implication for health policy/practice/research/medical education:

Ethanol extract of Curcuma heyneana possesses significant hepatoprotective activity and might be used as adjunctive therapy for prevention of liver injury mainly caused by drugs.

Please cite this paper as: Marianne M, Harahap U, Hasibuan PAZ, Thampati CM, Harefa HS. Hepatoprotective activity of the ethanol extract of Curcuma heyneana rhizome on isoniazid and rifampin-induced liver injury rats. J Herbmed Pharmacol. 2020;9(4):333-338. doi: 10.34172/jhp.2020.42.

\section{Introduction}

Based on the global tuberculosis report of the World Health Organization (WHO) in 2013, Indonesia was in position 9 with the incidence of 185 cases per 100000 population and ranked $3^{\text {rd }}$ in the south-east region with the incidence of 82799 new cases in 2012 (1). Isoniazid (INH) and rifampin (RIF) are the first lines in the therapy of tuberculosis (2). The utilisation of INH along with RIF produces toxic metabolites or oxidants such as acetylhydrazine $(\mathrm{AcHz})$ and hydrazine $(\mathrm{Hz})$ which can cause serious liver injury (3).

DILI or drug-induced liver injury is an important issue nowadays. DILI may occur to the tuberculosis patients who consume INH for 6 to 9 months, RIF for 4 months, or a combination of INH and RIF for 4 months (4). This problem limits the use of antituberculosis agents and may cause treatment failure or even resistance. Therefore, this problem must be figured out in order to make patients safe and comfortable in using antituberculosis agents without risk of liver damage.

Curcuma heyneana Val. \& Zijp. or temu giring is one of the medicinal plants that are grown in Indonesia. This plant belongs to Zingiberaceae family (5). People in Indonesia usually use the rhizome as a food ingredient 
or to cure many ailments. Even though it has been used traditionally for years, there is still lack of scientific information about the efficacy of this plant.

The rhizome of $C$. heyneana contains curcuminoid, oxycurcumenol, curcumenol, isocurcumenol, phytosterols stigmasterol, a-sitosterol, germacrone, dehydrocurdione, curcumanolide A, B, zerumbone, 1(10), 4(5)-diepoxygermacrone (6-9). The research about activity of $C$. heyneana is limited. So far, the research remains exploring the chemical compounds in the rhizome. Some researchs has found that the rhizome has activity as antibacterial (9), anti-inflammatory (10), antiaging (11) and antioxidant (12). However, the activity as hepatoprotective against INH and RIF has not been done. Based on the description above, the aim of this research was to investigate the hepatoprotective activity of $C$. heyneana against INH and RIF. Parameters of testing were secondary metabolites in the rhizome, antioxidant activity and biochemicals such as aspartate aminotransferase (AST) and alanine aminotransferase (ALT). Histological study of the liver was also conducted.

\section{Materials and Methods}

Materials

Fresh rhizome of $C$. heyneana was collected from Karo district, North Sumatera, Indonesia. Botanical identification and authentication were done in Indonesian Institute of Sciences in Bogor, Indonesia. The result is Curcuma heyneana Val \& Zijp (Number: 1367/IPH.1.02/ If.8/IX/2014). Materials were bought from various companies: Rifampin (Sandoz, Upper Bavaria, Germany), isoniazid (Sandoz, Upper Bavaria, Germany), sodium carboxymethyl cellulose (Sigma-Aldrich, Misouri, USA), catechin (Sigma-Aldrich, Misouri, USA), 2,2-diphenyl-1picrylhydrazyl (DPPH) (Sigma-Aldrich, Misouri, USA), ethanol (Merck, New Jersey, USA), ethyl acetate (Merck, New Jersey, USA), n-hexane (Merck, New Jersey, USA), reagent kit for ALT (DiaSys ${ }^{\circledR}$, Connecticut, USA), ascorbic acid (Sigma-Aldrich, Misouri, USA), reagent kit for aspartate aminotransferase (AST) (DiaSys ${ }^{\circledR}$, Connecticut, USA), neutral buffered formalin $10 \%$, eosin and hematoxylin stain. All biochemical measurements were carried out using a UV-Vis spectrophotometer (Thermo scientific, Massachusetts, USA).

\section{Animals}

Adult male Wistar albino rats (150-200 g), used in this study, were obtained from the Animal House Faculty of Pharmacy, Universitas Sumatera Utara. The animals were acclimatized for at least two weeks prior to the experiment. The rats had access to standard food and water ad libitum.

\section{Extraction of Curcuma heyneana leaves}

The fresh rhizomes of $C$. heyneana were dried in drying cabinet and continuously weighed until constant.
Extraction was done in $\mathrm{n}$-hexane, ethyl acetate and ethanol by maceration method. The filtrates were evaporated at $40^{\circ} \mathrm{C}$ under reduced pressure. The dried extract was stored at $2-8^{\circ} \mathrm{C}$ and re-constituted in carboxymethylcellulose sodium to be administrated to the experimental animals.

\section{Phytochemical screening}

The sample was screened for the following components: tannins, saponins, flavonoids, alkaloids, glycosides, steroids and triterpenoids.

\section{Antioxidant activity}

The extract of C. heyneana was tested for antioxidant activity by using DPPH method. DPPH solution was made in the concentration of $40 \mathrm{ppm}$, then maximum wavelength was measured. The extract solution was made in the concentrations of 20, 40, 60 and $80 \mathrm{ppm}$. The ascorbic acid solution was made in the concentrations of $1,2,4$ and $8 \mathrm{ppm}$. Afterwards, the extract was measured at $516 \mathrm{~nm}$. The activity of radical scavenging was calculated by using the equation below:

\section{The activity of radical scavenging $(\%)=$ $\frac{\text { Control absorbance-Sample absorbance }}{\text { Control absorbance }} \times 100 \%$}

Experimental design isoniazid-rifampin induced hepatotoxicity test

The rats were designated into 7 groups of 5 each. Treatments were done for 15 days as indicated in Table 1.

\section{Collecting of blood samples}

On the $16^{\text {th }}$ day of experiment, blood samples were collected from the rats by cardiac puncture under anaesthesia into a microtube. The blood samples were allowed to clot for 45 minutes at room temperature. Serum

Tabel 1. Experimental design

\begin{tabular}{|c|c|}
\hline Groups & Treatment \\
\hline $\begin{array}{l}\text { Group } 1 \text { (negative } \\
\text { control group) }\end{array}$ & $\begin{array}{l}\text { Animals received sodium carboxymethyl } \\
\text { cellulose + INH } 50 \mathrm{mg} / \mathrm{kg}+\text { RIF } 100 \mathrm{mg} / \mathrm{kg}\end{array}$ \\
\hline $\begin{array}{l}\text { Group } 2 \text { (tested } \\
\text { group) }\end{array}$ & $\begin{array}{l}\text { Animals received C. heyneana extract } 5 \text { mg/ } \\
\mathrm{kg}+\mathrm{INH} 50 \mathrm{mg} / \mathrm{kg}+\text { RIF } 100 \mathrm{mg} / \mathrm{kg}\end{array}$ \\
\hline $\begin{array}{l}\text { Group } 3 \text { (tested } \\
\text { group) }\end{array}$ & $\begin{array}{l}\text { Animals received C. heyneana extract } 25 \mathrm{mg} / \\
\mathrm{kg}+\mathrm{INH} 50 \mathrm{mg} / \mathrm{kg}+\text { RIF } 100 \mathrm{mg} / \mathrm{kg}\end{array}$ \\
\hline $\begin{array}{l}\text { Group } 4 \text { (tested } \\
\text { group) }\end{array}$ & $\begin{array}{l}\text { Animals received C. heyneana extract } 125 \\
\mathrm{mg} / \mathrm{kg}+\mathrm{INH} 50 \mathrm{mg} / \mathrm{kg}+\mathrm{RIF} 100 \mathrm{mg} / \mathrm{kg}\end{array}$ \\
\hline $\begin{array}{l}\text { Group } 5 \text { (tested } \\
\text { group) }\end{array}$ & $\begin{array}{l}\text { Animals received C. heyneana extract } 625 \\
\mathrm{mg} / \mathrm{kg}+\mathrm{INH} 50 \mathrm{mg} / \mathrm{kg}+\mathrm{RIF} 100 \mathrm{mg} / \mathrm{kg}\end{array}$ \\
\hline $\begin{array}{l}\text { Group } 6 \text { (positive } \\
\text { control group) }\end{array}$ & $\begin{array}{l}\text { Animals received catechins } 2 \mathrm{mg} / \mathrm{kg}+\mathrm{INH} 50 \\
\mathrm{mg} / \mathrm{kg}+\mathrm{RIF} 100 \mathrm{mg} / \mathrm{kg}\end{array}$ \\
\hline $\begin{array}{l}\text { Group } 7 \text { (normal } \\
\text { control group) }\end{array}$ & $\begin{array}{l}\text { Animals received standard rodent feed and } \\
\text { pure drinking water ad libitum }\end{array}$ \\
\hline
\end{tabular}


was separated by centrifugation at $3000 \mathrm{r} / \mathrm{min}$ for 15 minutes. Afterwards, animals were sacrificed by cervical dislocation and laparotomy for collecting the liver. Livers were then placed into neutral buffered formalin $10 \%$ for histological assessment.

Evaluation of various serum biochemical parameters Serum samples were analysed for ALT and AST using reagent kits from DiaSys ${ }^{\circledR}$.

Histological assessment

The liver was isolated, fixed in neutral buffered formalin $10 \%$, embedded in paraffin and cut into 4-5 $\mu \mathrm{m}$. Afterwards, the liver was deparafined, rehydrated and stained with hematoxylin subsequently eosin, after that, dehydrated with graded concentration alcohol and ultimately mounted (13).

\section{Statistical analysis}

Values were presented as mean \pm standard error $(n=5)$. Statistical analysis was carried out using one-way analysis of variance (ANOVA) followed by Tukey's multiple comparison tests using SPSS 19. Values were statistically significant at $P<0.05$.

\section{Results}

Phytochemical constituent

This research was initiated by extracting the rhizome using n-hexane, ethyl acetate and ethanol. Qualitative secondary metabolites analysis to the rhizome revealed the presence of steroids/triterpenoids in n-hexane extract. Various chemical compounds such as flavonoids, saponins, tannins, glycosides and steroids/triterpenoids found in ethyl acetate extract and ethanol extract.

Antioxidant activity

Antioxidant activity from extracts was performed by using DPPH radical scavenging method. The inhibitory concentration $\left(\mathrm{IC}_{50}\right.$ ) for $\mathrm{n}$-hexane extract was $837.29 \mathrm{ppm}$, ethyl acetate extract was $103.47 \mathrm{ppm}$, ethanol extract was $82.48 \mathrm{ppm}$, whereas vitamin $\mathrm{C}$ was $3.13 \mathrm{ppm}$. Based on this result, ethanol extract was later used for in vivo testing.

Hepatoprotective activity

The hepatoprotective activity of $C$. heyneana against INH and RIF was carried out for 15 days. The result of the activity can be seen in Figure 1.

Based on Figure 1, administration of INH-RIF significantly increased AST and ALT compared to normal control group $(P<0.01)$. C. heyneana at the doses of 5, 25, 125 and $625 \mathrm{mg} / \mathrm{kg}$ significantly prevented the elevation ALT and AST level compared to negative control group ( $P$ $<0.01$ ) in a dose-dependent manner.

At the doses of 25,125 and $625 \mathrm{mg} / \mathrm{kg}$, the effect of the extract toward ALT and AST level were the same as the positive control group as well as normal control group. It means that at the minimum dose of $25 \mathrm{mg} / \mathrm{kg}$, the extract could totally prevent the liver from injury.

After the surgical operation, macroscopic appearance of the liver was observed. The livers belong to treatment groups obviously had different colours compared to negative control. The livers of negative control group were pale red with white spot while tested groups were red-brownish. At the dose of $5 \mathrm{mg} / \mathrm{kg}$, the liver was pale red without white spot. As the dosage was increased, the intensity of the colour of the liver became darker and closer to the colour of positive control and normal control that was red-brownish. There was a strong correlation between AST and ALT levels with the macroscopic appearance of the liver. The pictures can be seen in Figure 2.

After macroscopic analysis, histological analysis was carried out. The results can be seen in Figure 3.

Based on Figure 3, all hepatocytes in all groups underwent hydropic degeneration. Necrosis occurred only in the dose of 5 and $25 \mathrm{mg} / \mathrm{kg}$. Doses of 125, 625, positive control and normal control did not show any sign of necrosis.

The liver of negative control, the dose of $5 \mathrm{mg} / \mathrm{kg}$

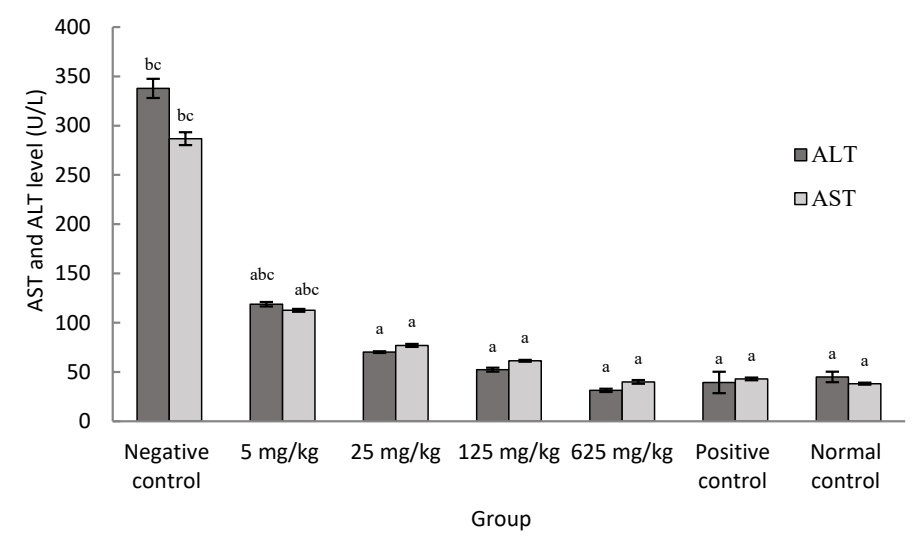

Figure 1. Effect of $C$. heyneana on serum biochemical parameters in antitubercular drugs-induced hepatotoxicity in rats (mean $\pm S E$, $n=5$ ). aP $<0.01$ as compared to the negative control group, ${ }^{b} P<0.01$ as compared to the positive control group, ${ }^{c} P<0.01$ as compared to the normal control group. 


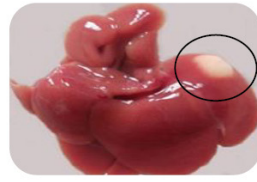

a

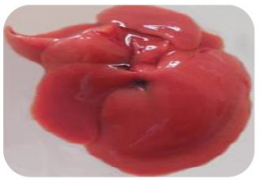

b

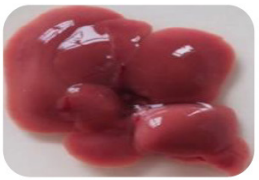

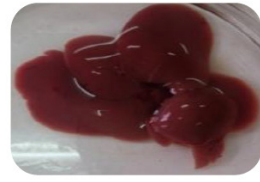

d

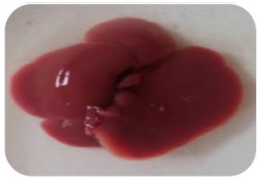

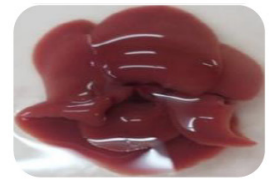

f

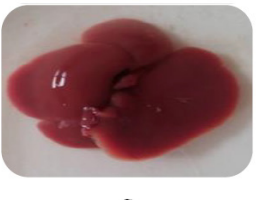

Figure 2. Macroscopic view of the liver;(a) negative control, (b) dose $5 \mathrm{mg} / \mathrm{kg}$, (c) dose $25 \mathrm{mg} / \mathrm{kg}$, (d) dose $125 \mathrm{mg} / \mathrm{kg}$, (e) dose $625 \mathrm{mg} / \mathrm{kg}$, (f) positive control, (g) normal control.
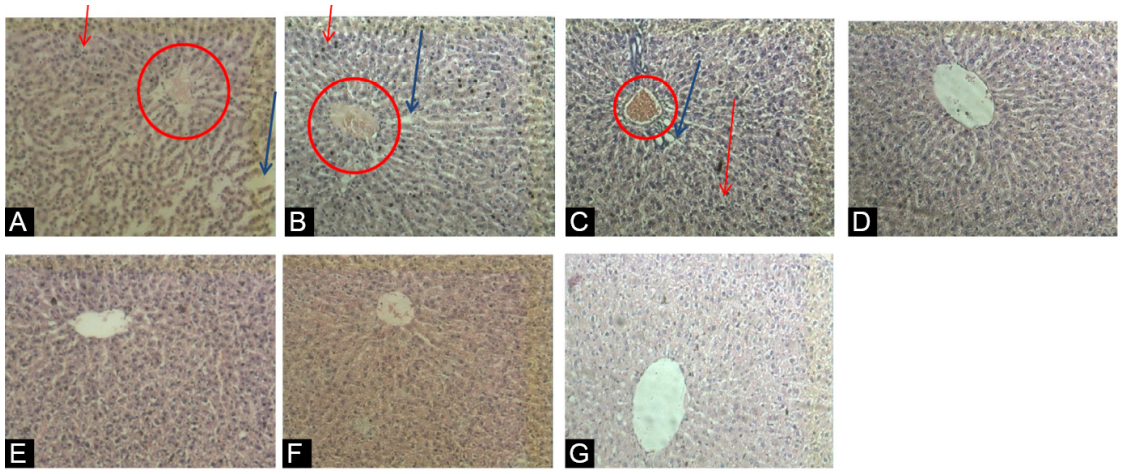

Figure 3. Microscopic view of the hepatocytes. The red circle is a congested central vein, the red arrow is necrotic hepatocyte and the blue arrow is dilated sinusoid. (A) negative control: congested central vein, necrotic hepatocyte and dilated sinusoid. (B) extract $5 \mathrm{mg} / \mathrm{kg}$ : congested central vein, necrotic hepatocyte and dilated sinusoid. (C) extract $25 \mathrm{mg} / \mathrm{kg}$ : congested central vein, necrotic hepatocyte and dilated sinusoid. (D) extract $125 \mathrm{mg} / \mathrm{kg}$ : normal central vein, normal hepatocyte, normal sinusoid. (E) Extract $625 \mathrm{mg} / \mathrm{kg}$ : normal central vein, normal hepatocyte, normal sinusoid. (F) positive control normal central vein, normal hepatocyte, normal sinusoid. $(G)$ normal control: normal central vein, normal hepatocyte, normal sinusoid.

as well as the dose of $25 \mathrm{mg} / \mathrm{kg}$ underwent injury in hepatocytes which was marked with sinusoidal dilatation and congestive of the central vein caused by endothelium cells lysis. The death nucleus appeared small and solid (pycnotic nucleus) (14).

In groups 125 and $625 \mathrm{mg} / \mathrm{kg}$, there was no significant injury compared to negative control. It proved that the administration of $C$. heyneana could protect the liver from damage.

\section{Discussion}

INH is a drug choice in treatment of tuberculosis. INH undergoes metabolism in the liver and produces metabolites such as $\mathrm{AcHz}$, isonicotinic acid, $\mathrm{Hz}$, diacetylhydrazine (DiAcHz), and acetylisoniazid (AcINH) (15). Next, $\mathrm{AcHz}$ and $\mathrm{Hz}$ are oxidized by microsomal enzymes P450 especially CYP2E1 into radical metabolites. These metabolites may cause hepatotoxicity. In this study, INH was administrated with RIF. Pretreatment with P450 inducers, such as RIF, raised the yield of radical metabolites dramatically. These radical metabolites later bind to the acetyl group of liver protein covalently and cause liver injury (16).
AST and ALT are the enzymes that can be found in the liver. ALT is more specific than AST in detecting liver damage whereas AST can be found not only in the liver but also in the heart, muscle, kidney as well as brain. Injury in these organs, release these enzymes and travel into blood. Therefore these enzymes are used as biomarkers in liver injury (17). In this research, administration of INH and RIF generated elevation of AST and ALT more than two fold. However, administration of ethanol extract of $C$. heyneana inhibited the elevation of AST and ALT. This result showed that the extract could prevent the damaging in the liver.

Administration of INH and RIF concomitantly, usually causes hepatic oxidative stress. This effect is protected by glutathione, the endogenous antioxidant with thiols group as reducing agent (18). The injury in hepatocytes is associated with significant decline of glutathione as well as antioxidant enzyme system (19). Later, the cell undergoes inflammation and death. In this research, administration of $C$. heyneana prevented the congested central vein, necrotic hepatocytes and dilated sinusoid. Co-administration of ethanol extract of C. heyneana prevented the induction of oxidative stress in INH-RIF 
co-exposed animals. The prevention of oxidative stress by extract was depicted as normal morphology in the animals liver. In contrast, the animals co-exposed to INH-RIF alone (negative control) showed histological lesions which ranged from congested central vein, necrosis hepatocyte as well as dilated sinusoid. These results suggest that INHRIF-induced liver injury can be prevented by supporting the cellular antioxidant defense mechanism activated by ethanol extract of C. heyneana.

Based on the phytochemical screening of ethanol extract of C. heyneana, revealed the presence of flavonoids, saponins, tannins, glycosides and steroids/triterpenoids. In vitro antioxidant test using DPPH method exhibited the ethanol extract of $C$. heyneana possessed strong antioxidant activity. Flavonoid was suspected to be responsible for the potency of antioxidant. Functional hydroxyl groups in flavonoids mediate their antioxidant effects by scavenging free radicals. In addition to that, flavonoids also activate glutathione peroxidase system as protective enzyme and inhibit the enzymes which are involved in reactive oxygen species generation $(20,21)$. Therefore, in this research, administration of extract for 2 weeks is suggested to induce protective enzyme that can tackle reactive metabolites generated from metabolism of RIF and INH. Ultimately, the extract serves as hepatoprotective and anti-inflammatory agent.

Curcuma heyneana also contains curcuminoid (22). Curcuminoid comprises curcumin, demethoxycurcumin andbisdemethoxycurcumin. Curcumin is main polyphenol found in the rhizome of Zingiberaceae. The synonym of curcumin (1,7-bis(4-hydroxy-3-methoxyphenyl)-1,6heptadiene-3,5-dione) is diferuloymethane. Polyphenol has a property as antioxidant related to reducing agent, acting as donor of electron or hydrogen which stabilizes or delocalizes unpair electron (23-25). In addition, curcumin may also stimulate antioxidant enzyme activity like glutathione peroxidase, superoxide dismutase and catalase. Curcumin is capable of scavenging oxygen free radicals such as superoxide anions and hydroxyl radicals which are important in initiation of lipid peroxidation $(26,27)$. The radicals $\mathrm{AcHz}$ and $\mathrm{Hz}$ may cause toxicity in the liver by lowering the existing antioxidant. Therefore, availability of curcumin in the rhizome of $C$. heyneana may protect the liver cells from oxidation by two mechanisms, directly by stabilizing or delocalizing unpair electron or indirectly by stimulating antioxidant activity (28).

\section{Conclusion}

The ethanol extract of $C$. heyneana rhizome at doses of 25,125 and $625 \mathrm{mg} / \mathrm{kg}$ may possess activity to protect the liver. For that reason, C. heyneana has potential to be developed as adjunctive therapy in prevention and treatment of antitubercular drug-induced liver injury. Further investigations are needed to isolate, identify and characterize the active compounds and to determine the exact mechanisms of actions.

\section{Acknowledgement}

The authors are gratefully to the Faculty of Pharmacy, Universitas Sumatera Utara, which has facilitated this research.

\section{Authors' contributions}

MM conceptualized the research and prepared the draft of manuscript; UH reviewed the literature and analyzed the data; PAZ prepared the draft; CMT conducted the research and analyzed the data; HSH conducted the research and analyzed the data. All authors read and approved the final report.

\section{Conflict of interests}

The authors declare no conflict of interest.

\section{Ethical considerations}

The studies were conducted according to protocols approved by institutional ethical committee No. 082/ KEPH-FMIPA/2015.

\section{Funding/Support}

None.

\section{References}

1. World Health Organization. Global tuberculosis report 2013. Available From: http://apps.who.int/iris/ handle/10665/91355.

2. World Health Organization. Treatment of tuberculosis guidelines. $4^{\text {th }}$ ed. Geneva: WHO; 2010.

3. Tafazoli S, Mashregi M, O’Brien PJ. Role of hydrazine in isoniazid-induced hepatotoxicity in a hepatocyte inflammation model. Toxicol Appl Pharmacol. 2008;229(1):94-101. doi: 10.1016/j.taap.2008.01.002.

4. American Thoracic Society/Centers for Disease Control and Prevention. Targeted tuberculin testing and treatment of latent tuberculosis infection. Am J Respir Crit Care Med. 2000'161(3):S221-47. doi: 10.1164/ajrccm.161. supplement_3.ats600.

5. Christoper B. RHS AZ. Encyclopedia of Garden Plants. $3^{\text {rd }}$ ed. London: Dorling Kindersley; 2003.

6. Sukari MA, Wah TS, Saad SM, Rashid NY, Rahmani M, Lajis NH, Hin TYY. Bioactive sesquiterpenes from Curcuma ochrorhiza and Curcuma heyneana. Nat Prod Res. 2010;24(9):838-45. doi: 10.1080/14786410903052951.

7. Bos R, Windono T, Woerdenbag HJ, Boersma YL, Koulman A, Kayser O. HPLC-photodiode array detection analysis of curcuminoids in Curcuma species indigenous to Indonesia. Phytochem Anal. 2007;18(2):118-122. doi:10.1002/pca.959

8. Firman K, Kinoshita T, Itai A, Sankawa U. Terpenoids from Curcuma heyneana. Phytochemistry. 1988;27(12):38873891.

9. Diastuti H, Syah YM, Juliawaty LD, Singgih M. Antibacterial activity of germacrane type sesquiterpenes from Curcuma heyneana Rhizomes. Indones J Chem. 2014;14(1):32-36.

10. Cho W, Nam JW, Kang HJ, Windono T, Seo EK, Lee KT. 
Zedoarondiol isolated from the rhizome of Curcuma heyneana is involved in the inhibition of iNOS, COX-2 and pro-inflammatory cytokines via the downregulation of NF- $\mathrm{B}$ pathway in LPS-stimulated murine macrophages. Int Immunopharmacol. 2009;9(9):1049-57. doi: 10.1016/j. intimp.2009.04.012.

11. Kusumawati I, Kurniawan KO, Rullyansyah S, Prijo TA, Widyowati R, Ekowati J, Matsunami K. Anti-aging properties of Curcuma heyneana Valeton \& Zipj: A scientific approach to its use in Javanese tradition. J Ethnopharmacol. 2018;225:64-70. doi: 10.1016/j.jep.2018.06.038.

12. Chen IN, Chang CC, Ng CC, Wang CY, Shyu YT, Chang TL. Antioxidant and antimicrobial activity of zingiberaceae plants in Taiwan. Plant Foods Hum Nutr. 2008;63(1):15-20. doi: 10.1007/s11130-007-0063-7.

13. Cardiff RD, Miller CH, Munn RJ. Manual hematoxylin and eosin staining of mouse tissue sections. Cold Spring Harbor Protocols. 2014;2014(6):pdb-rot073411.

14. Price SA, Wilson LM, Pathophysiology:Clinical Concepts of Disease Processes. 6th ed. New York, USA: McGraw-Hill; 1997.

15. Preziosi P. Isoniazid:metabolic aspects and toxicological correlates. Curr Drug Metab. 2007;8(8):839-851.

16. Wang P, Pradhan K, Zhong XB, Ma X. Isoniazid metabolism and hepatotoxicity. Acta Pharm Sin B. 2016;6(5):384-92. doi: 10.1016/j.apsb.2016.07.014.

17. Ortega-Alonso A, Stephens C, Lucena M, Andrade R. Case characterization, clinical features and risk factors in druginduced liver injury. Int J Mol Sci. 2016;17(5):714-9.

18. Chowdhury A, Santra A, Bhattacharjee K, Ghatak S, Saha DR, Dhali GK. Mitochondrial oxidative stress and permeability transition in isoniazid and rifampicin induced liver injury in mice. J Hepatol. 2006; 45(1):117-26.

19. Attri S, Rana SV, Vaiphei K, Sodhi CP, Katyal R, Goel RC, et al. Isoniazid-and rifampicin-induced oxidative hepatic injury-protection by N-acetylcysteine. Hum Exp Toxicol. 2000;19(9):517-522. doi: 10.1191/096032700674230830.

20. Kumar S, Pandey AK. Chemistry and biological activities of flavonoids:an overview. Sci World J. 2013;2013:162750. $10.1155 / 2013 / 162750$.

21. Nagata H, Takekoshi S, Takagi T, Honma T, Watanabe K. Antioxidative action of flavonoids, quercetin and catechin, mediated by the activation of glutathione peroxidase. Tokai J Exp Clin Med. 1999;24(1):1-11

22. Firman K, Kinoshita T, Akiko I, Ushio S. Terpenoids from Curcuma heyneana. Phytochemistry. 1988;27(12):38873891. doi: 10.1016/0031-9422(88)83038-3.

23. Rice-Evans C, Miller N, Paganga G. Antioxidant properties of phenolic compounds. Trends Plant Sci. 1997;2(4):152-9. doi:10.1016/S1360-1385(97)01018-2.

24. Aggarwal BB, Harikumar KB. Potential therapeutic effects of curcumin, the anti-inflammatory agent, against neurodegenerative, cardiovascular, pulmonary, metabolic, autoimmune and neoplastic diseases. Int J Biochem Cell Biol. 2009;41(1):40-59. doi: 10.1016/j.biocel.2008.06.010.

25. Gupta SC, Patchva S, Aggarwal BB. Therapeutic roles of curcumin: lessons learned from clinical Trials. AAPS J. 2013;15(1):195-218. doi: 10.1208/s12248-012-9432-8

26. Girish C, Pradhan SC. Drug development for liver diseases; focus on picroliv, ellagic acid and curcumin. Fundam Clin Pharmacol. 22(6):623-32. doi: 10.1111/j.14728206.2008.00618.x.

27. Kaur G, Tirkey N, Bharrhan S, Chanana V, Rishi PK, Chopra K. Inhibition of oxidative stress and cytokine activity by curcumin in amelioration of endotoxin-induced experimental hepatoxicity in rodents. Clin Exp Immunol. 2006;145(3):13-21.

28. Nasri H, Sahinfard N, Rafieian M, Rafieian S, Shirzad M, Rafieian-Kopaei M. Turmeric: A spice with multifunctional medicinal properties. J Herbmed Pharmacol. 2014;3(1):5-8. 